\title{
MAPPING CHILDREN'S LIFE-WORLDS: A CONTENT-ANALYTICAL STUDY OF DRAWINGS OF FAVOURITE GIFTS
}

\author{
KRISTIINA KRUUSE \\ PhD Student \\ Faculty of Social Sciences, Institute of Social Studies \\ University of Tartu \\ Lossi 36, 51003 Tartu, Estonia \\ e-mail: kristiina.kruuse@emor.ee \\ VERONIKA KALMUS \\ Professor of Sociology \\ Faculty of Social Sciences, Institute of Social Studies \\ University of Tartu \\ Lossi 36, 51003 Tartu, Estonia \\ e-mail: veronika.kalmus@ut.ee \\ PILLE RUNNEL \\ Research Director-Deputy Director \\ Estonian National Museum \\ Muuseumi tee 2, 60532 Tartu, Estonia \\ e-mail: pille.runnel@erm.ee \\ ANDRA SIIBAK \\ Professor of Media Studies \\ Faculty of Social Sciences, Institute of Social Studies \\ University of Tartu \\ Lossi 36, 51003 Tartu, Estonia \\ e-mail: andra.siibak@ut.ee
}

\begin{abstract}
What children count as their favourite things tell us not only about children but also about their social and cultural experiences. This study, ${ }^{*}$ based on the outcomes of a children's drawing competition organised by the Estonian National Museum and applying a combined framework of visual sociology and participatory research, proposes an innovative angle to using the museum's experimen-
\end{abstract}

* The preparation of this article was supported by a grant from the Estonian Ministry of Education and Research (IUT 20-38). 
tal approach to contemporary collecting of cultural heritage. This large-sample ( $n=926)$ content-analytical study of children's favourite gifts gives a rich ethnographic and sociological perspective on children's life-worlds. On the one hand, the children's wishes reflected contemporary global trends in technology and commercialisation. On the other hand, the children's prevailing dream of having a pet shows loneliness shaped by societal changes, including urbanisation and changing family models and time regimes.

KEYWORDS: life-world • gifts • child-centric research • draw-and-write method $\bullet$ societal changes

\section{IN T RODUCTION}

Growing up today is shaped by an interplay of changes occurring at different levels or systems of Urie Bronfenbrenner's (1979) ecological framework for human development. The pluralisation of family models, increasing individual and family mobility, mediatisation, commercialisation, globalisation, and general value changes are just a few prominent examples of the on-going transformation processes. The increasing pace of societal change and technological development, described and explored within the theoretical paradigm of social acceleration (Rosa 2013), and the theory of mediatisation (for example Lundby 2014), influence the material, social and symbolic environment of contemporary childhoods, and the ways children themselves experience, interpret and value their contexts of growing up.

To conceptualise the integrity of children's perceptions of these changing contexts, we employ the notion of life-world, developed within the phenomenological tradition of sociology (Schütz and Luckmann 1973). In Alfred Schütz's conception, life-world is defined as a subjective perception of the world (Schütz and Luckmann 1973), expressed through values, attitudes, ideas and preferences (Masso et al. 2020). Described as the world of lived experience inhabited by us as conscious beings, and incorporating the way in which phenomena (objects, events, emotions) appear to us in our conscious experience or everyday life (Husserl 1970), the life-world is a timeless yet sensitive construct that can also be used as a valuable and comprehensive conceptual tool to study children's perceptions of their changing environments.

The life-world is in constant and dynamic interaction with the material and technological environments. The duality of the relationship between the life-world and material objects in Anthony Giddens' (1984) sense implies that things and technologies enable as well as restrict the agency of human beings. This dialectics is further discussed in an increasingly popular theoretical concept of mediatisation that many authors (for example Hjarvard 2008; Krotz 2009; Livingstone 2009; Lundby 2014; Couldry and Hepp 2016) consider a new key theory in understanding changes in media-saturated societies and cultures. The main claim is that everything - our culture, society, politics, everyday practices as well as our life-world - is mediated (Livingstone 2009; Hepp et al. 2015; Paus-Hasebrink 2018). Media and communication technologies increasingly shape all spheres of social life "from the global and public to the most intimate, from weirdest niche fandom to the highly profitable mass market. Nothing remains unmediated, in the raw." (Livingstone 2011: 1472) Childhood and children's play are mediatised, too, 
being increasingly influenced by the logic of the media (ibid.; Hjarvard 2014). Although classical toys such as bricks, toy cars, etc., have not lost their relevance, they are in constant competition with immaterial playthings such as video and online games (ibid.). Furthermore, in the indirect form of mediatisation, 'classical' toys are increasingly influenced by the media's symbolic content and business cycle: toys and children's games are very probably inspired by media characters (ibid.; Nevski and Siibak 2016).

Conceptualising mediatisation theoretically has led to an academic discussion about how to study children, their socialisation and life-worlds in these rapidly changing environments. Researchers from various disciplines call for a greater interdisciplinarity - for instance, in media studies (Livingstone 2011) or ethnography and folkloristics (Briggs 2020). The debates, furthermore, address the challenges that ethnographers face when conducting fieldwork in mediatised fields (Eisewicht and Kirschner 2015) as well as a need to reconfigure folkloristics and media studies in a way that highlights the parallel theoretical turns these fields have undertaken in recent years (Briggs 2020).

In proceeding from these research needs and following life-world analytical ethnography (Eisewicht and Kirschner 2015), and in line with Schütz and Thomas Luckmann's (1973) perspective on the life-world, we will explore children's drawings of their favourite gifts as ethnographic material and as a subjective, contextualised and situation-specific reflection of their material and immaterial culture, including children's preferences and value orientations. In empirical terms, we aim to answer the question, what are the prevailing patterns of gift types, what are their symbolic characteristics, and what meanings do children ascribe to them?

Our case study was carried out within the framework of a wider ethnographic research project performed by the Estonian National Museum, which set up different research interventions in order to understand museum-audience relationships (Pruulmann-Vengerfeldt et al. 2014; Runnel and Pruulmann-Vengerfeldt 2014). A large sample of children's drawings was collected through a nationwide competition - one of the research activities within the project addressing the museum engagement of different audience segments, including children, whose contemporary life-worlds had remained underrepresented (less collected and less researched) at the museum. The goal of the drawing competition was twofold: a) to increase the relevance of the museum in children's daily activities by making their voices heard; and b) to find approaches which support contemporary museum collecting of children's life-world related material.

Until this case study, regular drawing competitions arranged by the museum were not linked to other museum activities, except educational ones. The ethnographic project on museum communication employed drawing competitions as the existing museum practice and type of audience relationship to support further participatory and research processes within the museum. This paper, in turn, applies different research disciplines such as media studies and sociology in using and interpreting the collected material, which traditionally would have been accessed only by museum curators or humanities scholars. The paper, thus, represents an innovative attempt to find new disciplinary collaborations to enrich knowledge production and find and test new data sources with which to study contemporary life-worlds.

The format of the drawing competition used in our case study, with children accomplishing the creative exercise at school, has both advantages and limitations as a data collection method. Another aim of this study, thus, is to discuss, in methodological 
terms, whether, how and with what concessions children's drawings (as ethnographic material) can be analysed as a reflection of their material and immaterial culture, with the objective of providing insights for further ethnographic study of children's lifeworlds.

\section{GIFTS AND FAVOURITE THINGS AS AN EXPRESSION OF VALUES AND SOCIETAL CHANGES}

Our possessions contribute to and reflect our identities to a major extent (Belk 1988); our favourite things relate particularly strongly to the self and identity (Csikszentmihalyi and Halton 1981). In fact, as indicated in Schultz Kleine et al. 1995: 327, "possessions to which there is attachment help narrate a person's life story; they reflect 'my life'"'. Children often receive their favourite possessions as gifts, given to them by significant others to symbolise or celebrate important life events, family relationships or holidays.

Anthropologist Marcel Mauss has argued in his classic work The Gift (1966 [1925]) that objects exchanged as gifts have high social value related to the relationship between the giver and the receiver rather than the actual worth of the gift. Thus, giftgiving is related to moral bonds (Mauss 1966 [1925]). Giving and receiving gifts build relationships between people. It is an important social mechanism, governed by social norms and customs. Russell Belk (1977) defines four functions of gift-giving: 1) communication; 2) social exchange; 3) economic exchange; and 4) socialisation. Buying gifts increases retail sales dramatically during Christmas and other holidays (Davies et al. 2010), indicating that gift-giving is a ritualised process and stressing the significance of gift-giving in the formation of social patterns. Gifted objects, thus, may entail an extra symbolic value and are also strongly linked with the socialisation of children (Banks 1979).

This study focuses on elementary school children aged about 7-11, which is an analytical stage of development when children increasingly begin to understand the value of possessions based on their social meaning and significance (John 1999). Moreover, children's understanding of the market, brands and advertising becomes more complex. They also learn to see the social world from the perspective of others, making them more adoptive and thoughtful in how they express their desires (ibid.).

Over centuries conceptualisations of childhood have changed; among other notable aspects, play has become a central part of childhood and child development: "play is the work of childhood" (Best 1998: 199). Thus, a significant part of children's lifeworld and childhood culture is characterised by the things and toys that children use in their daily routines. Photographer Gabriele Galimberti (2014), who travelled to 58 countries to take photos of children with their most prized possessions, concluded that children's favourite toys reflected the needs and realities of their cultures and thus were also deeply rooted in social norms. This is in line with David Buckingham's (2011) perspective that studying children's commodities is not just about objects, but more significantly about the many ways it affects children's environment and their social and cultural experiences.

One of the major changes in children's toy preferences began in the early 2000s when computer and console games and multimedia toys started to dominate children's play 
preferences instead of the previously popular war toys that "constituted a widespread and male-dominated phenomenon" in the mid-1980s (Wegener-Spöhrig 2008: 20). This marked a shift in the nature of toys from material to increasingly immaterial (Hjarvard 2014). Numerous studies (for example Livingstone 2011; Hjarvard 2014) have continuously demonstrated the trend that children in urban Western societies are currently growing up in media-rich households where they are surrounded by a wide range of digital tools and devices. Previous studies using the draw-and-write/tell method (Marshall and Aitken 2006; Wiseman et al. 2019) on studying children's favourite possessions and activities have described the rise of technology: for example, nearly one third of young New Zealanders aged 8-11 $(n=84)$ drew electronic equipment (for example games console, TV, X-box, mobile phone, etc.) as their favourite possessions (Marshall and Aitken 2006).

In addition to technological equipment, contemporary children are also very much attached to their pets. David Marshall's and Robert Aitken's (2006) findings indicated that pets were by far the largest $(16.9 \%)$ single category of children's favourite possessions, as evidenced in their drawing exercise and described as 'friends'. Other authors (Bustad 1996; Fifield and Forsyth 1999) argue that children's close attachment to pets may have risen due to the changes in society and the labour market, as scholars have noted a significant positive correlation between parental employment level and acquiring a pet. On the one hand, full-time working parents may see pets as substitute transitional attachment objects (Melson 1988) that are able to compensate, at least in part, for the absence of parents. On the other hand, full-time working parents could also consider their children to be independent and responsible enough to take care of a pet.

In addition to pets, toys were listed among the most favourite possessions of children in the Marshall's and Aitken's (2006) study, accounting for $11.8 \%$ of the drawings. Children's preferences in toys, however, have been very gender-specific throughout much of childhood (Alexander 2003). A systematic analysis of previous research on gender differences in children's toy preferences by Todd et al. 2017 revealed that boys play more with male-typed toys and girls play more with female-typed toys due to both innate and social forces. Hence, as found by Waltraut Hartmann and Gilles Brougere (2008) in their study of 1,773 kindergarten children and 752 teachers in Austria, girls tended to prefer dolls, for example Barbie or Baby Born, and hand puppets, while boys rather played with toy vehicles and construction materials such as Lego and Playmobil. Even in Sweden, which has less gendered norms and values compared to many other countries, children's toy collections were strongly gender-typed (Nelson 2005): toys that represent the private sphere (doll houses, kitchen appliances, clothing accessories, jewellery, etc.) were more frequently preferred by girls, and toys that represent the public sphere (such as tools, machines and military equipment) were more frequently preferred by boys. Studies also indicate that girls' toys are associated with physical attractiveness, nurturing and domestic skills, while boys' toys are more often rated as violent, competitive, exciting and somewhat dangerous (Blakemore and Centers 2005). This suggests that children's preferences as well as adults' gift-giving behaviour (cf. Parsons and Ballantine 2008) are reflective of the traditional socialisation approach of society.

In comparison to the unanimous agreement on children's gender-specific preferences in toys, research findings differ with regard to the general importance that chil- 
dren tend to ascribe to brands. Although Marshall and Aitken (2006) described how children were more attached to products they owned rather than the brands, reflecting structural, and not so much symbolic, aspects of their favourite things, other studies have ascribed a greater significance to brands. For example, analysis of children's letters to Santa Claus (O'Cass and Clarke 2001; Halkoaho and Laaksonen 2009) indicate that children are brand oriented in their request behaviour: they identify clearly their desired brands and understand that different toy variants exist within a common brand name. Importantly, Aron O'Cass and Peter Clarke (2001) suggest that children tend to learn how to be successful by exercising different request strategies. For example, an analysis by Carole Slotterback (2006), who compared children's letters to Santa Claus over five years, revealed that although the overall level of politeness was strikingly low in children's requests for gifts, considerably more polite sentiments were expressed when requesting live animals for gifts (for example writing 16 "pleases" in a letter to request a puppy).

Children often justify their toy requests by mentioning the pleasure of playing and being interested in the toy (Hartmann and Brougere 2008). In interviews with 6-8-yearolds concerning the particular affordances and built-in features of toys leading to their toy preferences, Mertala et al. 2016 found that two kinds of value emerged: 1) those which reside in the toy itself, and 2) those which children give to toys. In fact, findings from Mertala et al. 2016 suggest that children are able to transform their cultural knowledge of what toys one should have into social capital among peers. Furthermore, their analysis revealed that children value toys not only as playthings but also as cultural artefacts, using them as one form of voice.

\section{DATA AND METHOD}

This study is based on the outcomes of a children's drawing competition organised by the Estonian National Museum. The national contest called on school-age children to draw and describe in writing either the best or the worst presents they had ever received, or the presents they were dreaming about. Children accomplished the drawing exercise at school (primarily in art classes), and teachers forwarded the works to the museum. The contest was part of an Estonian National Museum research project on museum communication, as part of which different participatory actions targeted various audience groups and engaged them in different activities from exhibition visiting to contemporary collecting of cultural heritage. In these activities, there was a need to find a good balance between the goals set by the fields of cultural participation and the field of social research, in which the activities were simultaneously located. Cultural participation in a museum aims for democratic engagement (Runnel and PruulmannVengerfeldt 2014), whereas a research project aims to produce knowledge within disciplinary boundaries and in a verifiable way (Runnel 2015).

This particular national drawing competition challenged the ways in which museums collect data about children and youth. The study was inspired by a set of theoretical and methodological considerations characteristic of the socio-constructive approach to the sociology of childhood in which children are regarded as competent social actors (ibid.). The participatory approach challenges traditional social research in which stud- 
ies of youth and especially children have generally involved collecting information from the children's parents, teachers and other adults. As researchers point out, information acquired from children themselves has been considered of secondary importance (Kyronlampi-Kylmanen and Maatta 2011). More recently, across different disciplines, a change has indeed taken place, and continues to do so, and children have emerged as a key source for understanding the dynamics of their everyday lives (Christensen and James 2000; Barker and Weller 2003; Einarsdóttir 2007).

Among the methodological tools applied within the child-centric approach, 'drawand-write' is an effective multimodal method that helps children to express their social and active self-concepts (Tatlow-Golden and Guerin 2010); thus, the material gathered serves our aims of studying aspects of children's life-world and material culture. Furthermore, previous research (Bremner 2008) has also found the method of "doing 'artwork"' to be effective when used to analyse children's favourite toy gifts, as well as when drawing favourite possessions (Marshall and Aitken 2006).

With 174 schools (about one third of all public schools in Estonia) and 3,225 children participating, the competition was the most popular drawing contest organised by the Estonian National Museum. This analysis focuses on elementary school children (aged 6-11) whose drawings formed about two thirds of the total corpus. We excluded some drawings that did not indicate whether the child liked or disliked the present, and set 10 drawings as the upper limit for sampling entries from the same school class. The final sample for this study comprised 969 depicted presents. Most of the children (95\%) drew the presents they liked or were dreaming about; thus, we decided to base this analysis only on children's favourite presents. Among the 926 drawings, 582 were authored by girls and 344 by boys. More than half of the authors came from cities or towns, while $41 \%$ were from smaller places with less than 1,000 inhabitants. The age groups from the first to the fourth school grade were almost equally represented.

We employed standardised content analysis to code the depicted presents. The coding guide consisted of 16 main categories and 233 subcategories, including the characteristics of the present (the occasion, type and brand), the giver of the present, and the reasons why children liked or disliked the present. To test the coding guide, five members of the research group individually coded 20 drawings. The initial inter-coder reliability was 0.89 . The research group refined the coding guide by elaborating on the instructions for coding the problematic categories, after which the drawings in the final sample were coded by one researcher. The process included qualitative content analysis of children's written comments on the drawings to find the most typical as well as exceptional reasonings for favourite presents. We use some of these to illustrate the results.

\section{GIRLS'AND BOYS’ FAVOURITE PRESENTS}

Our analysis suggests that pets such as dogs, cats, hamsters, chinchillas, rabbits, etc., were one of the most popular presents cherished by children - depicted in $15.5 \%$ of all girls' and $5.2 \%$ of boys' drawings ${ }^{1}$ (see Figures $1-2$ ). Children did not only dream about animals: in most cases (79\%) they drew their pet as the best present they had actually ever received, indicating that children are less likely to lose interest in such gifts. In 
children's own words, pets are so desired as gifts mainly because they are alive, react to children and enable them to take care of the pet. For instance, a girl described her cat in the following terms: "Most importantly, she is alive. I play with her all the time. I made her a necklace, but she doesn't like to wear it. She is my best friend." In fact, our analysis of the drawings and accompanying statements revealed that children often anthropomorphise their pets, describing them as real friends and companions who are there for them when they feel bored or lonely, and join in when they want to play. In another example, a boy wrote:

I wanted a dog because it is so boring to wait for my mum to get home from work. A dog was the dream of my life. I take him to bed with me every night and he is so happy when I arrive from school.

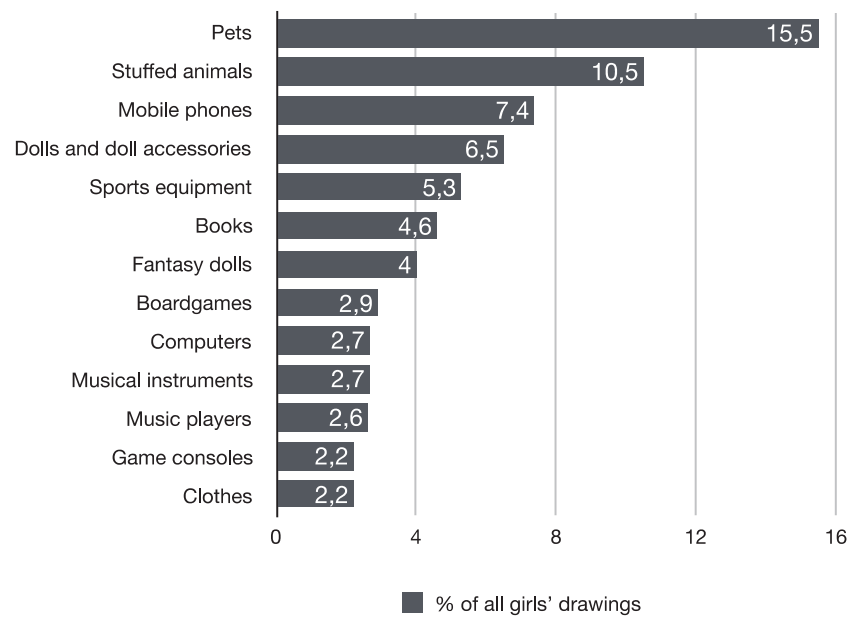

Figure 1. Most desired gifts by girls.

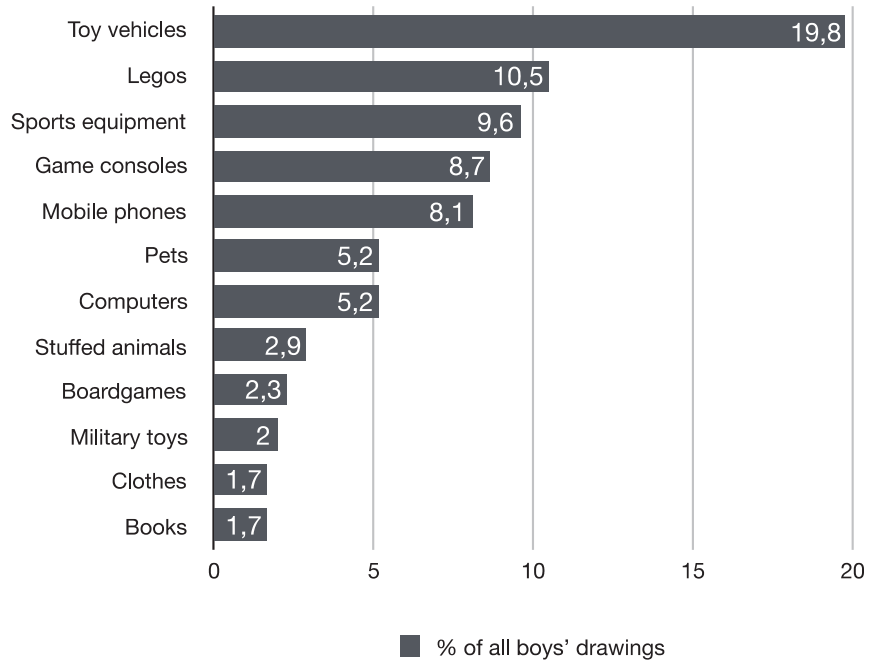

Figure 2. Most desired gifts by boys. 
Although there were some overlaps in the items making the TOP 13 list of girls' and boys' favourite presents (including, in addition to pets, everyday consumer and cultural goods such as ICT devices, sports equipment, books, card or board games, and clothes), the order of priorities differed considerably between the genders, indicating that children's favourite gift preferences and toy collections are still strongly gendertyped. For example, gender-specific tastes were revealed in the realm of stuffed toys, which girls considered one of their most favourite gifts ( $10.5 \%$ of girls vs $2.9 \%$ of boys), while boys revealed greater excitement and interest when receiving games consoles ( $8.7 \%$ of boys vs $2.2 \%$ of girls). Despite the fact that girls have not picked up digital gaming to such a significant extent, our analysis revealed that both genders shared an interest in acquiring ICT devices, especially mobile phones $(8.1 \%$ of boys vs $7.4 \%$ of girls) and laptops/computers (5.2\% of boys vs $2.7 \%$ of girls) as gifts.

Even though both boys' and girls' drawings often depicted their desire to live in a media-rich household, there was also evidence of children's continued interest in sport. Although boys had depicted sports equipment as their favourite gift somewhat more often $(9.6 \%$ vs $5.3 \%)$, girls' representation of this category is far from negligible. Girls as well as boys named books (4.6\% vs $1.7 \%)$ and card or board games $(2.9 \%$ vs $2.3 \%)$ as their favourite gifts, both representing types of items adults often consider to be good value-for-money for their educational depth or long-term amusement. Items of clothing were quite rarely spotlighted (2.2\% of girls vs $1.7 \%$ of boys) as favourite presents, indicating that clothes have become prosaic consumer goods, the purchase of which children do not consider highly significant.

Our sample also revealed several exclusively gender-specific preferences. For example, realistic and fantasy dolls, and music equipment were depicted as most favourable gifts only by girls (see Figure 1), whereas toy cars/vehicles, Lego/building bricks, and military toys were only named by boys (see Figure 2). While the findings are not overly surprising, they are reflective of the traditional socialisation approach of society.

The reasons for liking the presents, expressed by girls and boys, were also fairly different (Figures 3 and 4). Girls brought up attractive affordances activated by representational elements in toys: terms such as "it's beautiful", "it's cute/lovely", "it's dear to me", and "it's alive", appeared often in their reasoning; boys, however, mentioned stimulation-related values such as "it's cool" and "it's interesting". Girls and boys in our sample often also ascribed functional play value (Mertala et al. 2016), i.e. actionoriented reasoning (Eisenberg 1982) to their favourite gifts ("I like the activity related to it" and "I like to play with it"), but also expressed utilitarian values ("it's practical"), or self-centred personal values ("it made me happy", "I just wanted it" and "it was my dream") when describing their favourite gifts. Peer-group pressure ("my friends have it") or the social value of the toys, however, was not significant in children's reasoning. 


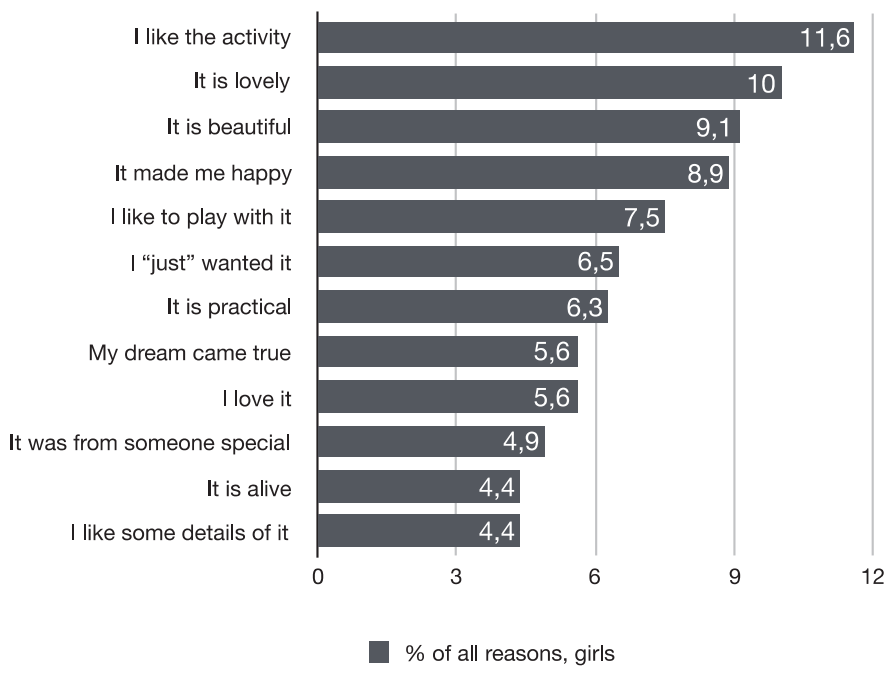

Figure 3. Reasoning for liking a present (girls).

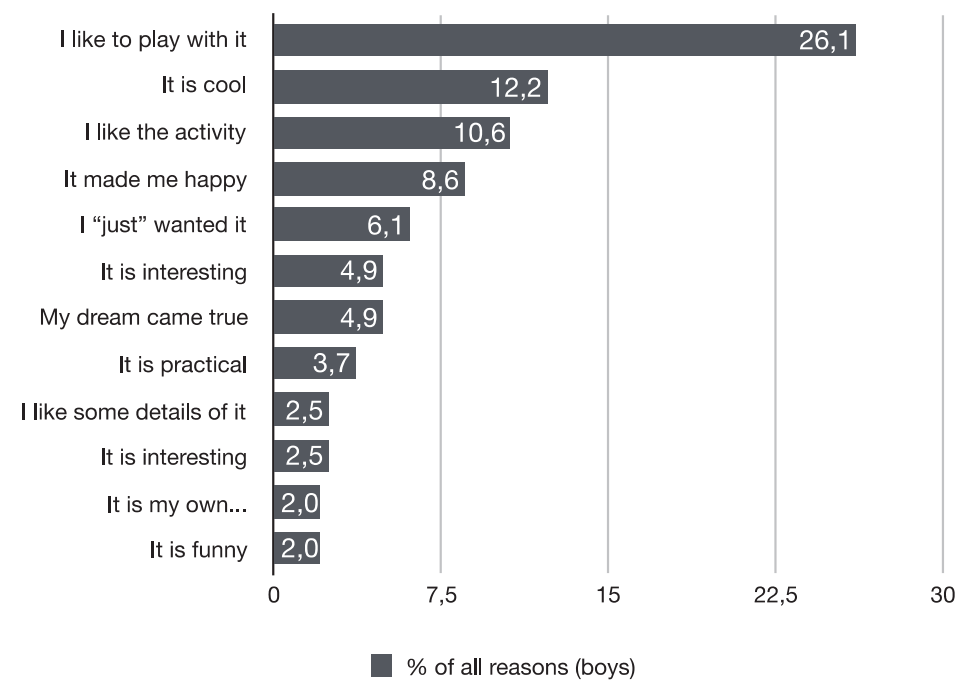

Figure 4. Reasoning for liking a present (boys).

\section{BRANDED PRESENTS}

Among favourite presents, less than one third (29\%) were branded (children had either written brand names in the picture or drawn logos). Interestingly, boys depicted more branded presents (37\% of their drawings) than girls did $(25 \%)$. The most popular brand among boys was Lego, which formed one quarter of all brands depicted by boys (Figure 5). On the one hand, this is related to children's language use as 'Lego' has become 
almost a synonym for various building bricks. On the other hand, a more detailed analysis suggests that Lego is a well-known brand among Estonian boys as they often mentioned specific sub-brands such as Lego City, Lego Chima, Lego Police, and others. Other popular brands among boys were Nintendo (9.3\% of brands), PlayStation (8.5\%), Apple (7\%), Samsung (7\%) and sports clothes brands such as Adidas, Nike, etc. (5\%).

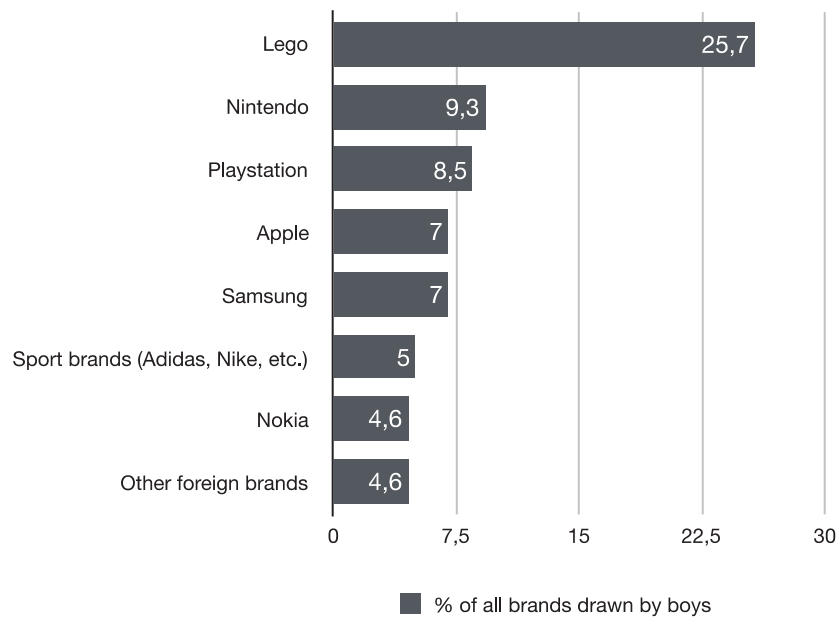

Figure 5. Brands drawn by boys.

Among girls, the most frequently depicted brand was Samsung $(12.7 \%$ of all the brands girls drew; Figure 6). The popularity of Samsung is related to reasonably priced mobile phones, which, furthermore, had a special series depicting a highly esteemed Estonian cross-media character Lotte the Dog. The second most popular brand among girls was Barbie (9.5\% of brands drawn), which was followed by Apple (7\%), Nintendo $(6.8 \%)$, Disney brands (6.2\%), Pet Shop (5.5\%), Monster High (5.5\%) and LG (5.5\%).

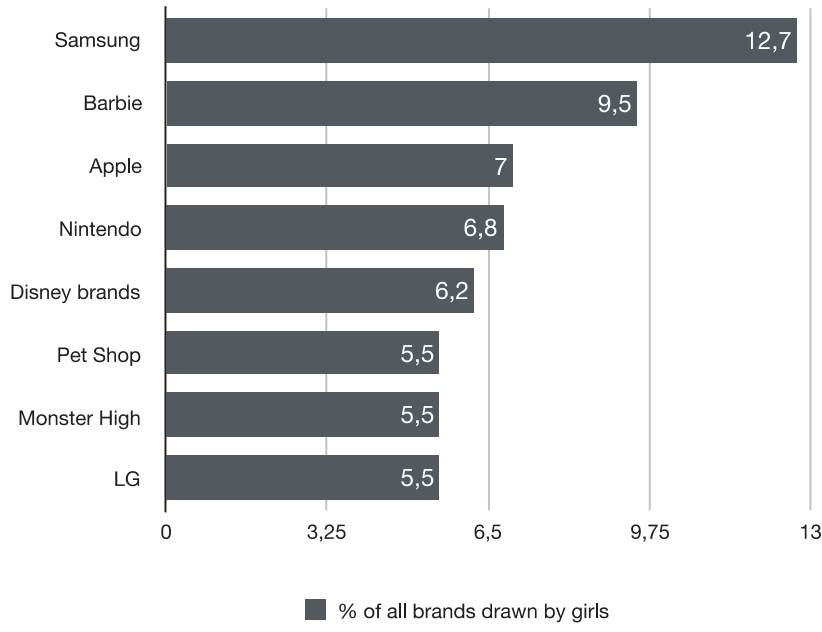

Figure 6. Brands drawn by girls. 
Altogether, the main branded items were toys and ICT devices. Branded clothes, with the exception of sports clothes, were not remarkably important for Estonian elementary school age children. In terms of the frequency of depiction, the most popular brands were of foreign origin. With the exception of Lego being most popular among Estonian boys, US and Asian companies dominated the frequency charts of depicted brands, reflecting global economic processes and marketing strategies. Correlation between the depiction of brands and where the children lived (cities versus small towns or the countryside) was not significant.

\section{CONCLUSIONS AND DISCUSSION}

This article has explored children's life-world and material culture through a large sample of drawings of favourite gifts. We proceeded from the perspective that our possessions reflect our identities (Belk 1988) and that children's favourite things are not only objects, but also a contemplation of their social and cultural experiences (Buckingham 2011). Empirical data for the analysis was collected in Estonia, a country that offers a suitable and intriguing case for our analysis because it is an emerging consumer society (see Wærdahl et al. 2009 for an overview) where traditional institutions (for example the family) have undergone noticeable changes during the post-Soviet transformations of the last three decades (Kutsar et al. 2012; Talves and Kalmus 2015).

The findings revealed both anticipated as well as surprising patterns. On the one hand, drawings of favourite gifts described the kind of typical child one would expect to find growing up in a modern, mediatising society with a commercialised culture: a child who likes Lego, dolls, toy vehicles, games consoles, ICT devices, Disney figures, etc. The popularity of these things is not surprising, considering global trends and previous studies of children's favourite toys (Marshall and Aitken 2006; Wegener-Spöhring 2008; Hjarvard 2014). On the other hand, the drawings and writings revealed a more surprising and thought-provoking perspective: pets were the favourite gift in our large sample. This firstly raises the question of whether this is a country-specific or more widespread phenomenon? It is likely that the latter is more probable as similar results the popularity of pets - have been described elsewhere in Western cultures (for example Marshall and Aitken 2006). Secondly, this finding elicits several interpretations regarding contemporary children's life-worlds.

Increasing concerns exist about human-animal relationships as characterised by the commodification of the companion animal. This was not manifest in the human-pet relationships children expressed in our study. In their written comments to drawings, children explained how they loved the fact that pets are real, they can play with them and take care of them. The desire for real, living company indicates children's loneliness, especially when considering how they anthropomorphise their pets, attributing to them the roles characteristic to friends, siblings and family (see the quotes in the findings section). Applying agency and kinship terminology to pets and constructing them as 'persons' (Charles and Davies 2008) rather than 'animals' shows a wider cultural trend and changing social connections. In fact previous research has shown that 7-10-year-old pet owners in California were as likely to talk with their pets about angry, sad, happy or secret experiences as with their siblings (Bryant 1985). Research evidence 
has thus led psychologist Gail Melson (2003) to suggest that children form emotional bonds with, and thus also draw emotional support from, their pets. This bond shares many of the features of children's significant ties with humans - reassurance, support, and the "contact comfort of touch" (Melson 2001: 6), meaning that these relationships are important in children's lives. Although toys are interactive and increasingly technologically advanced (toys can sing, talk, move, etc.), they are no substitute for a real companion. Forming significant emotional bonds, nurturing and anthropomorphising pets might also be linked to the importance of pets in exploring different sides of children's sense of self.

Another explanation for the importance of pets in Estonian children's life-world comes from the predominant family models and welfare and gender regimes: in twocareer families or single-parent households, the parents are engaged in paid work, which diminishes the amount of parental attention available to children at home (Kalmus and Roosalu 2012). While many countries (for example USA, Canada, UK, Australia, Norway, etc.) regulate the age at which children can be left at home alone, Estonian law does not provide explicit legal norms, and it is culturally acceptable to leave children of 7-8 years of age at home alone after school until the parents return. In part, families consider that pets compensate for the temporary absence of parents from home. An earlier study conducted in New Zealand supports this line of argumentation, finding that a significant positive correlation exists between the level of parental employment and acquiring a pet (Fifield and Forsyth 1999). Considering the high mediatisation of children's life-worlds (Hjarvard 2014), future research could explore whether parental reasoning for acquiring a pet is aimed at demediatising children's everyday lives by supporting their screen-free activities.

Another explanation for the popularity of pets, we propose, is connected to the scarcity hypothesis (Inglehart 1997), i.e. individuals place higher value on things that are short in supply. Rapid urbanisation, growing family mobility, changes in the labour market and increasing time pressure resulting from social acceleration (Rosa 2013) mean that having a pet is no longer taken for granted: it has become a deficiency value. Acquiring a living animal, which involves long-term responsibility, is therefore not an option many families are willing to consider: today, less than half of Estonians (48\%) have a pet (Kantar Emor 2020). Children's retrospective short stories and wishful contemplations about ideal gifts indicate that acquiring a pet is something they consider difficult, and really special. A study conducted in the United States supports this interpretation: children were extremely polite and convincing only when they requested a pet, whereas the overall level of politeness when expressing their Christmas wishes was surprisingly low (Slotterback 2006).

Another notable finding from our study indicates that children of younger school age were more attached to characteristics and functions of gifts than to symbolic characteristics such as brands. Less than one third of children depicted brands in their drawings of desired gifts. Preferring the functions and characteristics of gifts over brands at the younger school age (6-11) is in line with a study by Marshall and Aitken (2006), but more in contrast to other brand-specific studies (O'Cass and Clarke 2001; Halkoaho and Laaksonen 2009; Lopez and Rodriguez 2018) that describe children as both brandconscious and brand-oriented in their requests of things. It has to be acknowledged, though, that we did not seek to study brands in particular, but rather were interested in 
the objects children consider culturally meaningful despite their country of origin - an approach that is more in line with life-world analytical ethnography than with the paradigm of brand studies. The supranational reach of the toy industry and its marketing strategies was, however, clearly evident as the most popular brands among the children in our sample were of foreign origin, mainly from the United States or Asia.

Researching children's (as well as adults') life-worlds is methodologically challenging due to 1) the highly abstract nature of the concept, and 2) the fact that its constitutive phenomena are subjectively experienced. Researchers therefore have to find and improve ways of operationalising and describing a phenomenon that is not verbalised by participants, yet is reflective of the time they live in and experiences they have. To study the changing life-world of the adult population, an established research tradition in Estonia (Lauristin et al. 2017; Masso et al. 2020) has used representative questionnaire surveys, operationalising the concept of the life-world in terms of everyday practices of communication and media use, material and cultural consumption, civic participation and entrepreneurship, as well as various categories of social cognition (values, identities, beliefs and social self-positioning). In picking a child-centric approach (Kleine et al. 2016: 4), we decided to analyse a large sample of ethnographic data, i.e. children's drawings of their favourite gifts. We chose these because they represent relevant aspects of their everyday practices, value priorities and consumption preferences, and can be considered methodological proxies for the respective indicators in survey questionnaires. The draw-and-write method, furthermore, has often been implemented in studies that focus on experiences or views that might be difficult for a child to articulate; through the 'universal language' of drawings the method is applicable for materialising the immaterial (Lyon 2020: 4). Previous draw-and-write studies have also demonstrated that this method has the potential to bridge verbal language barriers (Renslow and Maupin 2017), thus representing a valuable mode of grasping children's life-worlds.

The format of the drawing competition, organised in cooperation with schools, does have some limitations. From the social scientific and consumer research perspective, one limitation lies in the fact that we were unable to discuss the task with the children beforehand or ask for their reflections or interpretations afterwards; neither could we include additional questions. From the ethnographic point of view, however, this 'naturally raw data' enabled us to study children's perspectives without any influence from the researchers, something that we propose is a strength.

Secondly, to what extent children actually depicted their most favourite presents remains unknown. Were these really the objects they deemed most relevant and valuable, and to what degree did they follow pragmatic considerations (for example did they choose objects they could draw well to succeed in the competition, or were they simply realising their first ideas to 'pass' the exercise)? When data are collected at school, teachers might play some role as 'gate-keepers' by selecting only those creative works they regard as presenting their school in a more positive light. Potential biases of social desirability or pragmatism are not unique to creative methods: the reliability of other data collection techniques such as surveys or interviews can also be reduced by the 'effect of answering for mark $\mathrm{A}^{\prime}$ in institutional contexts, especially schools; the proportion of the sample affected, however, is generally not significant (cf. Kalmus 2004). Our data, furthermore, included a few cases where two creative works resembled each 
other in terms of the depicted objects and/or the verbal arguments, evidencing peer influence. In the context of the overall sample size, however, the number of such cases was insignificant.

Large-scale samples of children's drawings as a data source and the robust coding scheme for content analysis developed for this study provide some perspectives for further ethnographic studies on children's life-worlds. Firstly, apart from museums, other cultural, education and entertainment institutions such as science and amusement centres, theme parks, etc., collect children's drawings either on the spot or remotely (for example by organising competitions). Large amounts of ethnographic material collected this way in different countries and the 'universal language' of drawing provides various opportunities for inter-sectoral and cross-cultural studies. Secondly, the method developed for this study can be used diachronically to compare analogous samples of children's drawings from different decades. The categories of object that are significant in children's lives could in this way serve as a sensitive 'cultural indicator', in George Gerbner's (1969) classical approach to analysing 'collective cultural life', and would, thus, enable us to reveal potential changes in children's life-worlds from a longer time perspective.

\section{NOTES}

1 As the proportion of girls among the participants was significantly higher, and children's preferences were gender-specific, we present the findings on figures by gender group.

\section{REFERENCES}

Alexander, Gerianne M. 2003. An Evolutionary Perspective of Sex-Typed Toy Preferences: Pink, Blue, and the Brain. - Archives of Sexual Behaviour 32 (1): 7-14.

Banks, Sharon. 1979. Gift-Giving: A Review and an Interactive Paradigm. - Advances in Consumer Research 6: 319-324.

Barker, John and Susie Weller. 2003. "Is It Fun?" Developing Children Centered Research Methods. - International Journal of Sociology and Social Policy 23 (1): 33-58. DOI: https://doi. org/10.1108/01443330310790435.

Belk, Russell W. 1977. Gift-Giving Behaviour. Faculty Working Papers. Urbana, IL; Champaign, IL: University of Illinois. https://archive.org/stream/giftgivingbehavi450belk?ref=ol\#page/n5/ mode/2up (accessed September 21, 2020).

Belk, Russell W. 1988. Possessions and the Extended Self. - Journal of Consumer Research 15 (2): 139-168. DOI: https://doi.org/10.1086/209154.

Best, Joel. 1998. Too Much Fun: Toys as Social Problems and the Interpretation of Culture. - Symbolic Interaction 21 (2): 197-212. DOI: https://doi.org/10.1525/si.1998.21.2.197.

Blakemore, Judith and Renee Centers. 2005. Characteristics of Boys' and Girls' Toys. - Sex Roles 53: 619-633. DOI: https://doi.org/10.1007/s11199-005-7729-0.

Bremner, Pauline. 2008. Gift Giving to Children at Christmas and Birthdays. A Conference Paper. - Annual Conference of the Academy of Marketing (AM2008): Reflective Marketing in a Material World, 8-10 July 2008, Aberdeen, UK. https://rgu-repository.worktribe.com/output/247930/ gift-giving-to-children-at-christmas-and-birthdays (accessed September 22, 2020). 
Briggs, Charles L. 2020. Moving Beyond "the Media": Critical Intersections between Traditionalization and Mediatization. - Journal of Folklore Research 57 (2): 81-117. DOI: https://doi. org/10.2979/jfolkrese.57.2.03.

Bronfenbrenner, Urie. 1979. The Ecology of Human Development. Cambridge, MA: Harvard University Press.

Bryant, Brenda K. 1985. The Neighborhood Walk: Sources of Support in Middle Childhood. - Monographs of the Society for Research in Child Development 50 (3): 122. DOI: https://doi. org/10.2307/3333847.

Buckingham, David. 2011. The Material Child: Growing up in Consumer Culture. Cambridge: Polity.

Bustad, Leo K. 1996. Recent Discoveries About Our Relationships with the Natural World. - Compassion: Our Last Great Hope - Selected Speeches of Leo K. Bustad. Renton, WA: Delta Society, $1-12$.

Charles, Nickie and Charlotte Aull Davies. 2008. My Family and Other Animals: Pets as Kin. Sociological Research Online 13 (5): 4. DOI: https://doi.org/10.5153/sro.1798.

Christensen, Pia Monrad and Allison James, eds. 2000. Research with Children: Perspectives and Practices. London: Falmer Press.

Couldry, Nick and Andreas Hepp. 2016. The Mediated Construction of Reality. Cambridge: Polity Press.

Csikszentmihalyi, Mikaly and Eugene Rochberg-Halton. 1981. The Meaning of Things: Domestic Symbols and the Self. New York, NY: Cambridge University Press. DOI: https://doi.org/10.1017/ CBO9781139167611.

Davies, Gary; Susan Whelan, Anthony Foley and Margaret Walsh. 2010. Gifts and Gifting. - International Journal of Management Reviews 12 (4): 413-434. DOI: https://doi.org/10.1111/j.14682370.2009.00271.x.

Einarsdóttir, Johanna. 2007. Research with Children:Methodological and EthicalChallenges. - European Early Childhood Education 15 (2): 197-211. DOI: https://doi.org/10.1080/13502930701321477.

Eisenberg, Nancy. 1982. The Development of Reasoning regarding Prosocial Behavior. - The Development of Prosocial Behavior. New York, NY: Academic Press, 220-248. DOI: https://doi. org/10.1016/B978-0-12-234980-5.50014-6.

Eisewicht, Paul and Heiko Kirschner. 2015. Giving in on the Field: Localizing Life-World Analytic Ethnography in Mediatized Fields. - Journal of Contemporary Ethnography 44 (5): 657-673. DOI: https://doi.org/10.1177/0891241615595437.

Fifield, Sarah and Darryl Forsyth. 1999. A Pet for the Children: Factors Related to Family Pet Ownership. - Anthrozoös 12 (1): 24-32. DOI: https://doi.org/10.2752/089279399787000426.

Galimberti, Gabriele. 2014. Toy Stories: Photos of Children from Around the World and Their Favorite Things. New York, NY: Abrams Image.

Gerbner, George. 1969. Toward 'Cultural Indicators': The Analysis of Mass Mediated Public Message Systems. - The Analysis of Communication Content: Developments in Scientific Theories and Computer Techniques, edited by George Gerbner in collaboration with Ole R. Holsti, Klaus Krippendorff, William J. Paisley and Philip J. Stone. New York, NY: Wiley, 123-132.

Giddens, Anthony. 1984. The Constitution of Society: Outline of the Theory of Structuration. Cambridge: Polity.

Halkoaho, Jenniina and Pirjo Laaksonen. 2009. Understanding What Christmas Gifts Mean to Children. - Young Consumers 10 (3): 248-255. DOI: https://doi.org/10.1108/17473610910986053.

Hartmann, Waltraut and Gilles Brougere. 2008. Toy Culture in Preschool Education and Children's Toy Preferences. - Toys, Games, and Media, edited by Jeffrey Goldstein in collaboration with David Buckingham and Gilles Brougere. London: Lawrence Erlbaum Associates Publishers, 37-54. 
Hepp, Andreas; Stig Hjarvard and Knut Lundby. 2015. Mediatization: Theorizing the Interplay between Media, Culture and Society. - Media, Culture E Society (2): 1-11. DOI: https://doi. org/10.1177/0163443715573835.

Hjarvard, Stig. 2008. The Mediatization of Society. - Nordicom Review 29 (2): 105-134. DOI: https:// doi.org/10.1515/nor-2017-0181.

Hjarvard, Stig. 2014. Mediatization and Cultural and Social Change: An Institutional Perspective. - Mediatization of Communication. Handbooks of Communication Science 21, edited by Knut Lundby. Berlin: De Gruyter, 199-226. DOI: https://doi.org/10.11606/issn.1982-8160.v8i1p2144.

Husserl, Edmund. 1970. The Crises of European Sciences and Transcendental Phenomenology. Evanston, IL: Northwestern University Press.

Inglehart, Ronald. 1997. Modernization and Postmodernization: Cultural, Economic, and Political Change in 43 Societies. Princeton, NJ: Princeton University Press.

John, Deborah Roedder. 1999. Consumer Socialization of Children: A Retrospective Look at Twenty-Five Years of Research. - Journal of Consumer Research 26 (3): 183-213. DOI: https://doi. org $/ 10.1086 / 209559$.

Kalmus, Veronika. 2004. What Do Pupils and Textbooks Do with Each Other? Methodological Problems of Research on Socialization through Educational Media. - Journal of Curriculum Studies 36: 469-485. DOI: https://doi.org/10.1080/00220270310001630670.

Kalmus, Veronika and Triin Roosalu. 2012. Institutional Filters on Children's Internet Use: An Additional Explanation of Cross-National Differences in Parental Mediation. - E-Youth: Balancing between Opportunities and Risks, edited by Michel Walrave in collaboration with Wannes Heirman, Sara Mels, Christiane Timmerman and Heidi Vandebosch. Oxford: Peter Lang Publishers House, 235-250.

Kantar Emor. 2020. "Kompass 2020" Eesti elanikkonna trendiuuring. Available upon request at https://www.kantaremor.ee/teenuse-kategooria/trendiuuringud/ (accessed September 29, 2020).

Kleine, Dorothy; Gemma Pearson and Sammia Poveda. 2016. Method Guide 8. Participatory Methods: Engaging Children's Voices and Experiences in Research. http://globalkidsonline.net/wp-content/uploads/2016/05/Guide-8-Participatory-methods-Kleine-Pearson-Poveda.pdf (accessed September 21, 2020).

Krotz, Friedrich. 2009. Mediatization: A Concept with Which to Grasp Media and Societal Change. - Mediatization: Concept, Changes, Consequences, edited by Knut Lundby. New York, NY: Peter Lang, 21-40.

Kutsar, Dagmar; Kairi Kasearu and Triin Kurrikoff. 2012. Family Trends and Changing Parenting Practices in Estonia. - Cognition, Brain, Behaviour: An Interdisciplinary Journal 16 (2): 171-190.

Kyronlampi-Kylmanen, Taina and Kaarina Maatta. 2011. Using Children as Research Subjects: How to Interview a Child Aged 5 to 7 Years. - Educational Research and Reviews 6 (1): 87-93.

Lauristin, Marju; Peeter Vihalemm, Veronika Kalmus, Margit Keller, Maie Kiisel, Anu Masso, Signe Opermann, Külliki Seppel and Triin Vihalemm. 2017. Teoreetiline hoovõtt: ühiskond ja elavik. - Eesti ühiskond kiirenevas ajas. Uuringu "Mina. Maailm. Meedia" 2002-2014 tulemused, edited by Peeter Vihalemm in collaboration with Marju Lauristin, Veronika Kalmus and Triin Vihalemm. Tartu: Tartu Ülikooli Kirjastus, 1-23.

Livingstone, Sonia. 2009. On the Mediation of Everything: ICA Presidential Address 2008. - Journal of Communication 59 (1): 1-18. DOI: https://doi.org/10.1111/j.1460-2466.2008.01401.x.

Livingstone, Sonia. 2011. If Everything Is Mediated, What Is Distinctive About the Field of Communication? - International Journal of Communication (5): 1472-1475.

Lopez, Alberto and Rachel Rodriguez. 2018. Children and Their Brands: How Young Consumers Relate to Brands. - Journal of Consumer Marketing 35 (2): 130-142. DOI: https://doi.org/10.1108/ JCM-06-2016-1842. 
Lundby, Knut. 2014. Introduction: Mediatization of Communication. - Mediatization of Communication. Handbooks of Communication Science 21, edited by Knut Lundby. Berlin: De Gruyter, 3-38. DOI: https://doi.org/10.1515/9783110272215.

Lyon, Philippa. 2020. Using Drawing in Visual Research: Materializing the Invisible. - The SAGE Handbook of Visual Research Methods, edited by Luc Pauwels and Dawn Mannay. London: Sage Publishing, 297-308. DOI: https://doi.org/10.4135/9781526417015.n18.

Marshall, David and Robert Aitken. 2006. Putting Brands in the Picture: Children's Drawings of Their Favourite Things. - Asia-Pacific Advances in Consumer Research 7, edited by Margaret Craig Lees, Teresa Davis and Gary Gregory. Sidney: Association for Consumer Research: 268-276.

Masso, Anu; Marju Lauristin, Signe Opermann and Veronika Kalmus. 2020. Applying the Morphogenetic Perspective for the Analysis of Estonian Social Transformations. - Researching Estonian Transformation: Morphogenetic Reflections, edited by Veronika Kalmus in collaboration with Marju Lauristin, Signe Opermann and Triin Vihalemm. Tartu: University of Tartu Press, $1-31$.

Mauss, Marcel. 1966 [1925]. The Gift: Forms and Functions of Exchange in Archaic Societies. London: Cohen and West. https://archive.org/details/giftformsfunctio00maus (accessed December 30, 2019).

Melson, F. Gail. 1988. Availability of and Involvement with Pets by Children: Determinants and Correlates. - Anthorozoos 2: 45-52. DOI: https://doi.org/10.2752/089279389787058181.

Melson, F. Gail. 2001. Why the Wild Things Are: Animals in the Lives of Children. Cambridge, MA: Harvard University Press.

Melson, F. Gail. 2003. Child Development and the Human-Companion Animal Bond. - American Behavioral Scientist 47 (1): 31-39. DOI: https://doi.org/10.1177/0002764203255210.

Mertala, Pekka; Hannele Karikoski, Liisa Tähtinen and Vesa-Matti Sarenius. 2016. The Value of Toys: 6-8-Year-Old Children's Toy Preferences and the Functional Analysis of Popular Toys. - International Journal of Play 5 (1): 11-27. DOI: https://doi.org/10.1080/21594937.2016.1147291.

Nelson, Anders. 2005. Children's Toy Collections in Sweden: A Less Gender-Typed Country? Sex Roles 52: 93-104. DOI: https://doi.org/10.1007/s11199-005-1196-5.

Nevski, Elyna and Andra Siibak. 2016. Mediation Practices of Parents and Older Siblings in Guiding Toddlers' Touchscreen Technology Use: An Ethnographic Case Study. - Media Education - Studi, richerche e buone pratiche 7 (2): 320-340.

O'Cass, Aron and Peter Clarke. 2001. Dear Santa, Do You Have My Brand? A Study of the Brand Requests, Awareness and Request Styles at Christmas Time. - Journal of Consumer Behaviour 2 (1): 37-53. DOI: https://doi.org/10.1002/cb.88.

Parsons, Andrew G. and Paul W. Ballantine. 2008. The Gifts We Buy for Children. - Young Consumers 9 (4): 308-315. DOI: https://doi.org/10.1108/17473610810920515.

Paus-Hasebrink, Ingrid. 2018. The Role of Media within Children's Socialization: A Praxeological Approach. - Communications: The European Journal of Communication Research 44 (4): 1-20. DOI: https://doi.org/10.1515/commun-2018-2016.

Pruulmann-Vengerfeldt, Pille; Taavi Tatsi, Pille Runnel and Agnes Aljas. 2014. Researching Audience in Museums: A Multimethod and Multisite Interventionist Approach. - Audience Research Methodologies Between Innovation and Consolidation, edited by Geoffroy Patriarche in collaboration with Helena Bilandzic, Jakob Linaa Jensen and Jelena Juršic. New York, NY; London: Routledge, 87-106.

Renslow, Jillian and Jonathan Maupin. 2017. Draw-and-Write Technique Elicits Children's Perceptions of Health in the USA and Guatemala. - Health Education Journal 77 (1): 15-29. DOI: https://doi.org/10.1177/0017896917735569.

Rosa, Hartmut. 2013. Social Acceleration: A New Theory of Modernity. New York, NY: Columbia University Press. DOI: https://doi.org/10.7312/rosa14834. 
Runnel, Pille. 2015. Post Scriptum. Making of: The Challenges of Exhibition Production. - Hopeless Youth, edited by Francisco Martinez and Pille Runnel. Tartu: Estonian National Museum, 526-544.

Runnel, Pille and Pille Pruulmann-Vengerfeldt, eds. 2014. Democratising the Museum: Reflections on Participatory Technologies. Frankfurt am Main: Peter Lang Verlag. DOI: https://doi. org/10.3726/978-3-653-03972-6.

Schultz Kleine, Susan; Robert E. Kleine and Chris T. Allen. 1995. How is a Possession "Me" or "Not Me"? Characterizing Types and an Antecedent of Material Possession Attachment. Journal of Consumer Research 22 (3): 327-343. DOI: https://doi.org/10.1086/209454.

Schütz, Alfred and Thomas Luckmann. 1973. The Structures of the Life-World. Evanston, IL: Northwestern University Press.

Slotterback, Carole. 2006. Terrorism, Altruism, and Patriotism: An Examination of Children's Letters to Santa Claus 1998-2002. - Current Psychology 25 (2): 144-153. DOI: https://doi. org/10.1007/s12144-006-1009-1.

Talves, Kairi and Veronika Kalmus. 2015. Gendered Mediation of Children's Internet Use: A Keyhole for Looking into Changing Socialization Practices. - Cyberpsychology: Journal of Psychosocial Research on Cyberspace 9 (1). DOI: https://doi.org/10.5817/CP2015-1-4.

Tatlow-Golden, Mimi and Suzanne Guerin. 2010. My Favourite Things to Do and My Favourite People: Exploring Salient Aspects of Children's Self-Concept. - Childhood: A Global Journal of Child Research 17 (4): 545-562. DOI: https://doi.org/10.1177/0907568210364667.

Todd, Brenda; Rico Antonio Fischer, Steven Costa, Amanda Roestorf, Kate Harbour, Paul Hardiman and John A. Barry. 2017. Sex Differences in Children's Toy Preferences: A Systematic Review, Meta-Regression, and Meta-Analysis. - Infant and Child Development 27. DOI: https:// doi.org/10.1002/icd.2064.

Wærdahl, Randi; Veronika Kalmus and Margit Keller. 2009. Consumer Socialisation and Value Orientations among Estonian and Chinese Young People. - Children E Society 25: 127-138. DOI: https://doi.org/10.1111/j.1099-0860.2009.00271.x.

Wiseman, Nicola; Cristin Rossmann, Jessica Lee and Neil Harris. 2019. "It's Like You Are in the Jungle": Using the Draw-and-Tell Method to Explore Preschool Children's Play Preferences and Factors That Shape Their Active Play. - Health Promotion Journal of Australia 30: 85-94. DOI: https://doi.org/10.1002/hpja.209.

Wegener-Spöhring, Gisela. 2008. War Toys in the World of Fourth Graders: 1985 and 2002. -Toys, Games, and Media, edited by Jeffrey Goldstein in collaboration with David Buckingham and Giller Brougere. London: Lawrence Erlbaum Associates Publishers, 19-36. 